PontifícIa UnIVERSIDADE CATÓlica do RIO dE JANEIRO

\title{
DIFERENÇA DAS PERFORMANCES DAS AÇÕES DA MAGAZINE LUIZA E LOJAS AMERICANAS EM 2020
}

\section{Daniel Vibranovski Costa}

Trabalho de Conclusão de Curso

Centro de CIÊnCIAS SOCIAIS - CCS

DePARTAMENTO de AdMINISTRAÇÃo

Graduação em Administração de Empresas 


\section{DIFERENÇA DAS PERFORMANCES DAS AÇÕES DA MAGAZINE LUIZA E LOJAS AMERICANAS EM 2020}

Trabalho de Conclusão de Curso, apresentado ao programa de graduação em Administração da PUC-Rio como requisito parcial para a obtenção do título de graduação em Administração.

Orientadora: Graziela Fortunato 
Ao infinito e além.

LIGHTYEAR, Buzz. Toy Story. 


\section{Agradecimentos}

À minha mãe, Betty e meu pai, José Carlos; ao meu amigo Diego; à minha namorada, Stella; à minha orientadora, Graziela; e a todos os professores que me engrandeceram ao longo da vida. 


\section{Resumo}

COSTA, Daniel Vibranovski. Diferença das performances das ações da Magazine Luiza e Lojas Americanas em 2020. Rio de Janeiro, 2021. 28 p. Trabalho de Conclusão de Curso - Departamento de Administração. Pontifícia Universidade Católica do Rio de Janeiro.

Em 2020, na bolsa de valores brasileira, houve a diferença de 106,86 pontos percentuais entre a rentabilidade das ações MGLU3 e LAME3, das empresas Magazine Luiza e Lojas Americanas, respectivamente. Faltam estudos que expliquem essa diferença no ano em questão. Dessa maneira, devido à importância para os investidores e para as próprias empresas, o objetivo deste artigo é entender os principais motivos dessa diferença, sendo que ambas as empresas pertencem ao mesmo setor, varejo, operam no mesmo país, Brasil, e vendem pela mesma moeda, o Real. A pesquisa realizada será uma pesquisa exploratória, por meio dos relatórios trimestrais divulgados de ambas as empresas, dos anos de 2019 e 2020, levando em consideração os dados da economia brasileira nesses mesmos anos.

\section{Palavras-chave}

Magazine Luiza; Lojas Americanas; diferença de rentabilidade das ações; 2020; varejo; mercado financeiro; bolsa de valores; Brasil.

\section{Abstract}

COSTA, Daniel Vibranovski. The difference between Magazine Luiza and Lojas Americanas stocks in 2020. Rio de Janeiro, 2021. 28 p. Trabalho de Conclusão de Curso - Departamento de Administração. Pontifícia Universidade Católica do Rio de Janeiro.

In 2020, in the Brazilian stock exchange, there was a difference of 106,86 percentual points between the stocks MGLU3 and LAME3, of the companies Magazine Luiza and Lojas Americanas, respectively. There is a lack of studies directed to this matter. With that in mind, due to the importance of this matter to investors and for the own companies, the objective of this article is to better understand the principals causes of this difference, knowing that the two companies work at the same business, retail, at the same country, Brazil, and 
selling at the same coin, the Real. The research will use the exploratory method, using the trimestral report disclosed by the companies, between 2019 and 2020, matter of fact the data of the Brazilian macroeconomy at the same Years.

\section{Key-words}

Magazine Luiza; Lojas Americanas; difference between the profitability of the stocks; retail; financial market; stock exchange; Brazil. 


\section{Sumário}

10 tema e o problema de estudo 1

1.1. Introdução ao tema e ao problema do estudo 1

1.2. Objetivo do estudo 1

1.3. Objetivos intermediários do estudo 2

1.4. Delimitação e foco do estudo 2

1.5. Relevância e Contribuição do estudo 2

1.6. Estrutura do estudo 3

2 Referencial teórico 4

2.1. Análise fundamentalista 4

2.2. Análise Relativa 4

2.3. Cenário macroeconômico 8

2.4. Trabalhos Recentes sobre o Tema 9

3 Métodos e procedimentos de coleta e de análise de $\begin{array}{ll}\text { dados do estudo } & 10\end{array}$

3.1. Tipo de Pesquisa 10

3.2. Amostra e Coleta de dados 10

3.3. Variáveis e Tratamento dos dados 10

3.4. Indicadores Financeiros 11

3.5. Indicadores do Ambiente Macroeconômico 15

4 Apresentação e análise dos resultados 18

4.1. $O 1^{\circ}$ trimestre de $2020 \quad 18$

4.2. $O 2^{\circ}$ trimestre de 2020

4.3. $O 3^{\circ}$ trimestre de $2020 \quad 21$

4.4. $04^{\circ}$ trimestre de 2020

5 Conclusões e recomendações para novos estudos 24

5.1. Sugestões e recomendações para novos estudos 25

6 Referências Bibliográficas 26 


\section{Lista de Tabelas}

Tabela 1 - Indicadores de Liquidez........................................................ 11

Tabela 2 - Indicadores de Endividamento ................................................... 12

Tabela 3 - Indicadores de Gestão de Ativos ................................................ 12

Tabela 4 - Indicadores de Rentabilidade ................................................... 13

Tabela 5 - Indicadores de Mercado ......................................................... 13

Tabela 6 - Variação dos ativos na bolsa de valores......................................... 14

Tabela 7 - Variação do Ativo Total .......................................................... 14

Tabela 8 - Variação do Lucro Líquido ........................................................ 14

Tabela 9 - Variação do EBITDA …........................................................ 15

\section{Lista de Gráficos}

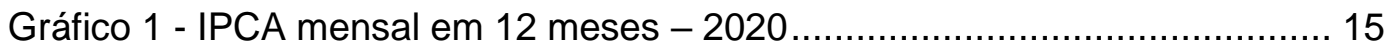

Gráfico 2 - Meta para taxa Selic entre 2019 e 2020....................................... 16

Gráfico 3 - Variação do PIB ocorrida entre 2019 e 2020 ................................ 16

Gráfico 4 - Desemprego no Brasil - IBGE ................................................ 17 


\section{0 tema e o problema de estudo}

\subsection{Introdução ao tema e ao problema do estudo}

Em 2020, houve uma disparidade entre as performances das ações da Magazine Luiza e Lojas Americanas, códigos de negociação MGLU3 e LAME3. Enquanto a primeira performou em $+107,06 \%$, a segunda em $-0,20 \%$, entre os dias 2 de janeiro e 30 de dezembro de 2020, na bolsa de valores brasileira. Esses dados foram obtidos no campo de "cotações e gráficos" do site de relação com investidores de ambas as empresas.

As ações dessas empresas são negociadas na bolsa de valores brasileira, a B3. A Magazine Luiza tem $42 \%$ de suas ações ordinárias em circulação, e as Lojas Americanas têm $52,9 \%$ de suas ações em free float, e dessas, 22,44\% são as ações ordinárias, segundo o site de relação com investidores de cada empresa.

Ambas as empresas são do setor de varejo, entretanto, diferente do setor, as companhias ganharam força no crescimento das vendas no ano de 2020 . O setor de varejo no Brasil em 2020, segundo o IBGE, cresceu apenas 1,2\%, ante o crescimento de $1,8 \%$ em 2019. Nesse mesmo ano, as vendas totais da Magazine Luiza cresceram 66\% ante 51\% em 2019 e as vendas das Lojas Americanas cresceram 12,32\%, ante 7,16\% em 2019.

Ademais, desde antes de 2020, as duas empresas já possuíam infraestrutura para atender à demanda das vendas virtuais, com toda a operação em andamento, incluindo seus sites, sistemas de pagamentos, centros de distribuição e entregadores.

Por fim, comparando as duas empresas, já em 2019 as vendas virtuais da Magazine Luiza eram mais expressivas do que as das Lojas Americanas, visto que representaram 48,0\% das vendas totais, e o aplicativo da Magazine Luiza naquele momento alcançava 19 milhões de usuários ativos mensais.

\subsection{Objetivo do estudo}

O objetivo deste estudo é entender os motivos principais da diferença de rentabilidade de 106,86 pontos percentuais entre os ativos MGLU3 e LAME3 na B3, no ano de 2020. 
Tal ângulo de análise se mostra interessante e importante, pois ambas as empresas pertencem ao mesmo setor, varejo, operam no mesmo país, Brasil, e vendem pela mesma moeda, o Real.

\subsection{Objetivos intermediários do estudo}

Para se atingir o objetivo final proposto, este estudo prevê os seguintes objetivos intermediários a serem alcançados:

- Estudar os principais indicadores financeiros de cada empresa;

- Identificar a relevância de atividades ESG na performance das ações das companhias;

- Entender a interferência do risco da crise econômica global do coronavírus diante das ações MGLU3 e LAME3.

\subsection{Delimitação e foco do estudo}

A delimitação temporal se concentra em observar as empresas no ano de 2019 até o final de 2020, uma vez que, para analisar os indicadores financeiros de 2020, é preciso compará-los ao período anterior, 2019.

A proposta deste estudo é ser uma análise detalhada apenas da Magazine Luiza e Lojas Americanas. Isto é, o estudo não pretende analisar a performance das ações de outras empresas do setor de varejo brasileiras, nem empresas de varejo estrangeiras.

Doravante, também há uma delimitação geográfica restrita ao território brasileiro por se tratar de duas empresas que só têm operações no Brasil. Desse modo, os dados financeiros expostos são em moeda nacional (Real).

\subsection{Relevância e Contribuição do estudo}

O estudo se mostra relevante para investidores que tenham ações ou interesse em aplicar recursos na Magazine Luiza ou Lojas Americanas. Os resultados da pesquisa também poderão ser úteis para os executivos e conselho de ambas as empresas, de modo que possam comparar as performances das empresas em 2020.

Por fim, as informações que este estudo pretende produzir podem se mostrar de interesse para futuros pesquisadores do campo de avaliação de empresas do setor de varejo, pois poderão ter embasamento para suas pesquisas. 


\subsection{Estrutura do estudo}

O desenvolvimento deste trabalho obedece à seguinte organização: o primeiro capítulo que introduz o tema, contém os objetivos principais e intermediários do estudo; a delimitação e foco do estudo e sua relevância e contribuição. O segundo capítulo, que apresenta o referencial teórico, se compromete a estudar a análise fundamentalista; a análise relativa, com os principais indicadores financeiros a serem estudados; o cenário macroeconômico e os trabalhos recentes sobre o tema. O terceiro capítulo, que apresenta o método de coleta e análise de dados do estudo, contém o tipo de pesquisa; a amostra e coleta de dados; as variáveis e tratamento dos dados; os indicadores financeiros e os indicadores do ambiente macroeconômico. O quarto capítulo traz a análise dos resultados dos quatro trimestres do ano de 2020 e, por fim, o quinto capítulo traz a conclusão e as recomendações para novos estudos sobre o tema. 


\section{Referencial teórico}

\subsection{Análise fundamentalista}

Segundo Kobori (2019), a análise fundamentalista consiste na avaliação sobre a gestão da empresa, sua saúde financeira, o potencial de resultados e a projeção do valor das ações. Esses dados são obtidos através dos relatórios de Demonstração de Resultados do Exercício, Balanço Patrimonial e Fluxo de Caixa.

\subsection{Análise Relativa}

A análise relativa ou a análise de grupos comparáveis, segundo Ross, Westerfield e Jordan (2013) é a "identificação de empresas similares no sentido de que competem no mesmo mercado, possuem ativos semelhantes e operam de maneira parecida".

A análise relativa é feita por indicadores financeiros. Esses são ferramentas para comparar uma empresa com outra, ou até uma mesma empresa com seu passado, e são determinados a partir de informações financeiras.

Há os indicadores de liquidez, os quais mostram a capacidade da empresa de pagar as contas de curto prazo. No grupo estão, estão os Índice de Liquidez Corrente, de Liquidez Geral, de Liquidez Seca e de Liquidez Imediata.

O Índice de Liquidez Corrente avalia a condição de solvência de curto prazo da empresa, isto é, se ela tem condições de honrar integralmente as obrigações de curto prazo (Gitman, 2010).

$$
\text { Índice de Liquidez Corrente }=\frac{\text { Ativo Circulante }}{\text { Passivo Circulante }}
$$

Já o Índice de Liquidez Geral, tem a função de medir a capacidade da empresa em cumprir com suas obrigações no curto prazo, desse modo, representando a saúde do caixa (Ross; Westerfield; Jordan, 2013).

$$
\text { Índice de Liquidez Geral }=\frac{\text { Ativo Total }}{(\text { Passivo Circulante }+ \text { Passivo Não Circulante })}
$$


O Índice de Liquidez Seca assemelha-se ao de liquidez corrente, mas exclui do cálculo o estoque, que costuma ser o menos líquido dos ativos circulantes (Gitman, 2010).

$$
\text { Índice de Liquidez Seca }=\frac{(\text { Ativo Circulante }- \text { Estoque })}{\text { Passivo Circulante }}
$$

Por fim, o Índice de Liquidez Imediata, é a forma mais conservadora possível de avaliar a solidez financeira da empresa no curto prazo. Contudo, como qualquer indicador, é importante utilizá-lo em conjunto com outros indicadores, como o de liquidez corrente e liquidez seca. Dessa forma, o investidor conseguirá ter uma ideia melhor da capacidade financeira da companhia em cumprir com seus passivos de curto prazo (Gitman, 2010).

$$
\text { Índice de Liquidez Imediata }=\frac{\text { Caixa }}{\text { Passivo Circulante }}
$$

Há também os indicadores de endividamento, que medem a capacidade da empresa de saldar suas dívidas de longo prazo, ou mesmo analisa o grau de alavancagem financeira. Entre esses indicadores, há o Índice de Endividamento Geral, Índice de Endividamento Financeiro, Grau de Endividamento, Cobertura de Juros e a Cobertura de Caixa.

O Índice de Endividamento Geral mede o percentual do ativo que está sendo financiado por recursos de terceiros (Ross; Westerfield; Jordan, 2013).

$$
\text { Índice de Endividamento Geral }=\frac{(\text { Ativo Total }- \text { Patrimônio Líquido })}{\text { Ativo Total }}
$$

Já o Índice de Endividamento Financeiro, mede o percentual do ativo que depende de passivos financeiros ou onerosos (dívida) (Ross; Westerfield; Jordan, 2013).

$$
\text { Índice de Endividamento Financeiro }=\frac{\text { Passivo Oneroso }}{\text { Ativo Total }}
$$

O Grau de Endividamento mapeia o nível de alavancagem financeira da empresa, de modo a revelar a relação entre dívida com terceiros e acionista (Ross; Westerfield; Jordan, 2013).

$$
\text { Grau de Endividamento }=\frac{(\text { Passivo Circulante }+ \text { Passivo Não Circulante })}{\text { Patrimônio Líquido }}
$$


A Cobertura de Juros, por sua vez, avalia o impacto do serviço da dívida (juros) sobre a capacidade do negócio de gerar caixa (Ross; Westerfield; Jordan, 2013).

$$
\text { Cobertura de Juros }=\frac{\text { EBITDA }}{\text { Juros }}
$$

Por fim, a Cobertura de Caixa mede se a empresa tem capacidade de pagar os seus juros com o seu caixa (Ross; Westerfield; Jordan, 2013).

$$
\text { Cobertura de Caixa }=\frac{\text { Caixa }}{\text { Juros }}
$$

Há também os indicadores de Gestão de Ativos, que medem se a empresa é eficiente em usar seus ativos para gerar vendas. Entre esses indicadores, há o Giro do Ativo Total, Giro do Estoque e o Grau de Intensidade de Capital.

O Giro do Ativo Total observa a velocidade com que os ativos geram o faturamento bruto (Ross; Westerfield; Jordan, 2013).

$$
\text { Giro do Ativo Total }=\frac{\text { Vendas }}{\text { Ativo Total }}
$$

Já o Giro do Estoque mostra quantas vezes o estoque é mantido durante o ano (Ross; Westerfield; Jordan, 2013).

$$
\text { Giro do Estoque }=\frac{\text { Custo da Mercadoria Vendida }}{\text { Estoque }}
$$

Por fim, o Grau de Intensidade de Capital mede a estrutura necessária de ativos para sustentar o faturamento (Ross; Westerfield; Jordan, 2013).

$$
\text { Giro de Intensidade de Capital }=\frac{\text { Ativo Total }}{\text { Receita Bruta }}
$$

Há também indicadores de lucratividade ou rentabilidade. Esses indicadores se propõem a revelar se a empresa é rentável, de modo a medir o quão eficiente é a empresa de acordo com a administração de suas operações. Esses indicadores são as Margens Bruta, Operacional e Líquida, Retorno do Ativo (ROA) e Retorno de Capital Próprio (ROE).

A Margem Bruta revela o percentual de rentabilidade média que a empresa está obtendo na comercialização de seus produtos (Ross; Westerfield; Jordan, 2013). 


$$
\text { Margem Bruta }=\frac{\text { Lucro Bruto }}{\text { Receita Líquida }}
$$

A Margem Operacional quantifica o percentual de rentabilidade média que a empresa está obtendo com seu lucro da atividade econômica (Ross; Westerfield; Jordan, 2013).

$$
\text { Margem Operacional }=\frac{\text { Lucro Operacional }}{\text { Receita Líquida }}
$$

A Margem Líquida revela o percentual de rentabilidade média total que a empresa está obtendo (Ross; Westerfield; Jordan, 2013).

$$
\text { Margem Líquida }=\frac{\text { Lucro Líquido }}{\text { Receita Líquida }}
$$

Já o Retorno do Ativo (ROA) revela qual o desempenho da empresa na gestão de ativos, significando o retorno do negócio, baseado no lucro que o ativo gerou (Ross; Westerfield; Jordan, 2013).

$$
\text { Retorno do Ativo }(R O A)=\frac{\text { Lucro Líquido }}{\text { Ativo Total }}
$$

Por fim, o Retorno de Capital Próprio (ROE) mede o retorno que os acionistas estão obtendo com seus investimentos na empresa, significando o retorno do negócio, baseado no que o capital próprio gerou de lucro. (Ross; Westerfield; Jordan, 2013).

$$
\text { Retorno de Capital Próprio }(R O E)=\frac{\text { Lucro Líquido }}{\text { Patrimônio Líquido }}
$$

Ademais, há os indicadores de valor de mercado, que buscam revelar se a empresa está valorizada ou não no mercado, de modo a usar o preço da ação em cada indicador, para se chegar a uma conclusão. Entre esses, está o Lucro Por Ação (LPA), o Preço/Lucro (P/L) e o Preço/Valor Patrimonial (P/B).

O Preço/Lucro (P/L) mede quanto os investidores estão dispostos a pagar por real de lucro corrente. Normalmente, $\mathrm{P} / \mathrm{L}$ altos são associados a empresas que possuem ótimas perspectivas de crescimento futuro (Ross; Westerfield; Jordan, 2013). 


$$
\operatorname{Preço} / \operatorname{Lucro}(P / L)=\frac{\text { Preço por } A \text { ção }}{\text { Lucro por Ação }}
$$

Já o Preço/Valor Patrimonial (P/B) compara o valor de mercado do investimento em uma empresa a seu custo. Desse modo, significando que as ações estão sendo negociadas por tantas vezes o quanto tem de patrimônio (Ross; Westerfield; Jordan, 2013).

$$
\text { Preço/Valor Patrimonial }(P / B)=\frac{\text { Preço por Ação }}{\text { Valor Patrimonial por Ação }}
$$

Por fim, o Lucro por Ação (LPA) demonstra o lucro por ação (Ross; Westerfield; Jordan, 2013).

$$
\text { Lucro por Ação }(L P A)=\frac{\text { Lucro Líquido }}{\text { Número de Ações }}
$$

Há também a análise horizontal, que não é um indicador, mas auxilia nas análises relativas das empresas, seja ao longo da evolução no tempo, das contas da Demonstração do Resultado do Exercício e do Balanço Patrimonial, como as contas de Lucro Líquido, Lucro Operacional (EBITDA) e o Ativo Total, seja comparando tais performances entre empresas.

Em relação às contas contábeis, o Lucro Operacional (EBITD) é a resultante da atividade operacional da empresa, que ao retirar o efeito da depreciação temse o EBITDA, que mostra seu potencial de geração de caixa. Desse modo, é possível saber se ela é capaz de investir, pagar o Imposto de Renda, remunerar o capital de terceiros e dos acionistas. O Lucro Líquido, por sua vez, é a sobra líquida da Receita Bruta à disposição dos sócios, depois de descontadas todas as despesas, custos e impostos. Já o Ativo Total demonstra as contas de Bens e Direitos, ou seja, representando o tamanho da empresa. (Ross; Westerfield; Jordan, 2013).

\subsection{Cenário macroeconômico}

O ambiente de negócios em 2020 foi marcado pela pandemia da Covid-19, que dificultou as vendas presenciais, a partir de março no Brasil devido às medidas sanitárias de redução do horário de funcionamento das lojas, impostas por governos estaduais e municipais. 
De acordo com o portal de notícias G1, em março de 2020, houve decretos do governo do Estado e da Prefeitura de São Paulo suspendendo o atendimento presencial ao público em estabelecimentos comerciais e de prestação de serviços. Preliminarmente, esses decretos eram válidos por 15 dias, entre os dias 24 de março e 7 de abril de 2020, todavia foi estendido, segundo outra matéria do mesmo portal.

Junto à crise sanitária e às medidas de isolamento social, veio a crise econômica. No $2^{\circ}$ trimestre de 2020 , houve alta no desemprego e, como evidência da redução da atividade econômica, houve deflação e a redução do PIB, segundo o Instituto Brasileiro de Geografia e Estatística (IBGE), Banco Central do Brasil (BCB) e o IBGE, respectivamente.

Vale enfatizar que, diante da crise econômica, os bancos centrais mundiais, incluindo o brasileiro, baixaram as taxas de juros para diminuir o custo do dinheiro, estimulando a economia e evitando a quebra de empresas.

No ano de 2020, segundo o IBGE, o setor de varejo cresceu apenas 1,2\% em comparação com o ano anterior. Nesse ano, as vendas presenciais diminuíram e, tanto a Magazine Luiza quanto as Lojas Americanas tiveram as vendas online como a principal fonte de receita. Desse modo, 63,8\% da receita da Magazine Luiza e 66,1\% da receita das Lojas Americanas em 2020 foram provenientes do e-commerce, de acordo com os resultados do $4^{\circ}$ trimestre dessas empresas.

\subsection{Trabalhos Recentes sobre o Tema}

Träsel (2018) analisou os resultados da Magazine Luiza entre os anos 2013 e 2017 com base na análise dos indicadores e observou que a empresa apresentou os melhores indicadores de giro e de dispêndios de capital em comparação com as Lojas Americanas, que por sua vez apresentou as melhores liquidez e rentabilidade [...].

Já Silva (2020):

Com o decreto da quarentena e o distanciamento social, observou-se o aumento da utilização do e-commerce para as vendas digitais e as empresas brasileiras se viram obrigadas a migrarem para essa nova plataforma de vendas para atender as novas demandas do mercado.

[...] Com o uso constante da Internet como meio de comunicação, compra e venda, as pessoas mesmo em tempos de crise, continuam adquirindo produtos e realizando constantemente suas compras. 


\section{Métodos e procedimentos de coleta e de análise de dados do estudo}

Este capítulo abordará o tipo de pesquisa, a amostra e coleta de dados, as variáveis e tratamentos de dados, os indicadores financeiros e os indicadores do ambiente macroeconômico.

\subsection{Tipo de Pesquisa}

A pesquisa realizada será uma pesquisa exploratória, visto que, ao analisar os dados das empresas Magazine Luiza e Lojas Americanas, será explorado o tema da diferença da performance de suas ações na bolsa de valores em 2020.

Ato contínuo, a pesquisa foi realizada através dos relatórios trimestrais dos anos de 2019 e 2020 de ambas as empresas, levando em consideração também os dados macroeconômicos da economia brasileira.

\subsection{Amostra e Coleta de dados}

A investigação será qualitativa, visto que será aprofundado o estudo de apenas duas empresas, em um único país, e no período de apenas dois anos. A coleta de dados será feita a partir dos relatórios trimestrais, divulgados ao mercado, das empresas Magazine Luiza e Lojas Americanas; relatórios do BCB; e relatórios do IBGE, todos dos anos de 2019 e 2020.

Foram coletadas informações financeiras de ambas as empresas para calcular os indicadores financeiros e as análises horizontais, tais como Ativo e Passivo Circulantes, Passivo Não Circulante, Ativo Total, Patrimônio Líquido, Caixa, Juros, Custo do Produto Vendido, Estoque, Receita Bruta e Líquida, Lucro Bruto, Operacional e Líquido, número de ações da companhia e Preço por Ação.

\subsection{Variáveis e Tratamento dos dados}

A pesquisa fará a análise dos indicadores financeiros apenas dos anos de 2019 e 2020 a partir dos dados contábeis disponibilizados nos sites das empresas no campo de relação com investidores. 
De acordo com esses dados, no capítulo 3 serão explicitados indicadores de liquidez, endividamento, gestão de ativos, rentabilidade e valor de mercado. Serão exibidas também as análises horizontais do Ativo Total e Lucro Líquido.

Em seguida, serão estudados os principais índices macroeconômicos brasileiros em 2020, tais como o IPCA, PIB e a taxa básica de juros (taxa Selic).

\subsection{Indicadores Financeiros}

Das empresas Magazine Luiza e Lojas Americanas, foram extraídas as informações contábeis dos anos de 2019 e de 2020, para serem calculados os indicadores financeiros e as análises horizontais.

Tabela 1- Indicadores de Liquidez

INDICADORES DE LIQUIDEZ

\begin{tabular}{|c|c|c|c|c|c|c|c|c|c|c|}
\hline & \multicolumn{10}{|c|}{2020} \\
\hline & \multicolumn{2}{|c|}{$1^{\circ}$ trimestre } & \multicolumn{2}{|c|}{$2^{\circ}$ trimestre } & \multicolumn{2}{|c|}{$3^{\circ}$ trimestre } & \multicolumn{2}{|c|}{$4^{\circ}$ trimestre } & \multicolumn{2}{|c|}{ minigráficos } \\
\hline & MGLU3 & LAME3 & MGLU3 & LAME3 & MGLU3 & LAME3 & MGLU3 & LAME3 & MGLU3 & LAME3 \\
\hline Liquidez Corrente & 1,79 & 1,95 & 1,39 & 1,93 & 1,34 & 2,33 & 1,25 & 2,61 & & \\
\hline Liquidez Geral & 1,74 & 1,29 & 1,57 & 1,27 & 1,51 & 1,67 & 1,42 & 1,50 & $\gamma$ & \\
\hline Liquidez Seca & 1,10 & 1,53 & 0,95 & 1,61 & 0,87 & 1,94 & 0,81 & 2,27 & & \\
\hline Liquidez Imediata & 0,07 & 0,70 & 0,12 & 0,79 & 0,11 & 0,96 & 0,13 & 1,16 & & \\
\hline
\end{tabular}

\begin{tabular}{|c|c|c|c|c|c|c|c|c|c|c|}
\cline { 2 - 12 } \multicolumn{1}{c|}{} & \multicolumn{10}{c|}{2019} \\
\cline { 2 - 12 } \multicolumn{1}{c|}{} & \multicolumn{1}{c|}{$1^{\circ}$ trimestre } & \multicolumn{2}{c|}{$2^{\circ}$ trimestre } & \multicolumn{2}{c|}{$3^{\circ}$ trimestre } & \multicolumn{2}{c|}{$4^{\circ}$ trimestre } & \multicolumn{2}{c|}{ minigráficos } \\
\cline { 2 - 12 } \multicolumn{1}{c|}{} & MGLU3 & LAME3 & MGLU3 & LAME3 & MGLU3 & LAME3 & MGLU3 & LAME3 & MGLU3 & LAME3 \\
\hline Liquidez Corrente & 1,17 & 2,21 & 1,21 & 2,27 & 1,08 & 2,15 & 1,60 & 1,79 & \\
\hline Liquidez Geral & 1,33 & 1,22 & 1,35 & 1,25 & 1,32 & 1,28 & 1,62 & 1,29 & \\
\hline Liquidez Seca & 0,62 & 1,79 & 0,70 & 1,86 & 0,59 & 1,73 & 1,13 & 1,45 & \\
\hline Liquidez Imediata & 0,06 & 0,87 & 0,13 & 0,87 & 0,05 & 0,78 & 0,04 & 0,60 & \\
\hline
\end{tabular}

Entre as informações contábeis usadas para calcular os Indicadores de Liquidez, há:

- O Ativo Circulante e Passivo Circulante para calcular o Índice de Liquidez Corrente;

- O Ativo Total, Passivo Circulante e Passivo Não Circulante para calcular o Índice de Liquidez Geral;

- O Ativo Circulante, Estoque e Passivo Circulante para calcular o Índice de Liquidez Seca;

- O Caixa e o Passivo Circulante para calcular o Índice de Liquidez Imediata. 
Tabela 2 - Indicadores de Endividamento

INDICADORES DE ENDIVIDAMENTO

\begin{tabular}{|c|c|c|c|c|c|c|c|c|c|c|}
\hline & \multicolumn{10}{|c|}{2020} \\
\hline & \multicolumn{2}{|c|}{$1^{\circ}$ trimestre } & \multicolumn{2}{|c|}{$2^{\circ}$ trimestre } & \multicolumn{2}{|c|}{$3^{\circ}$ trimestre } & \multicolumn{2}{|c|}{$4^{\circ}$ trimestre } & \multicolumn{2}{|c|}{ minigráficos } \\
\hline & MGLU3 & LAME3 & MGLU3 & LAME3 & MGLU3 & LAME3 & MGLU3 & LAME3 & MGLU3 & LAME3 \\
\hline End. Geral & $57,49 \%$ & $77,69 \%$ & $63,79 \%$ & $78,48 \%$ & $66,19 \%$ & $60,00 \%$ & $70,28 \%$ & $66,73 \%$ & & \\
\hline End. Financeiro & $4,82 \%$ & $55,57 \%$ & $8,10 \%$ & $58,87 \%$ & $7,68 \%$ & $39,82 \%$ & $6,84 \%$ & $46,13 \%$ & & \\
\hline Grau Endiv. & $135,25 \%$ & $348,30 \%$ & $176,18 \%$ & $364,67 \%$ & $195,73 \%$ & $150,00 \%$ & $236,47 \%$ & $200,62 \%$ & 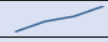 & \\
\hline Cobertura de Juros & 2,42 & 1,25 & 1,03 & 1,65 & 3,44 & 1,80 & 3,20 & 2,99 & 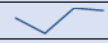 & $=$ \\
\hline Cobertura de Caixa & 2,83 & 14,93 & 7,87 & 18,71 & 7,50 & 24,97 & 10,67 & 33,88 & & $\longrightarrow$ \\
\hline
\end{tabular}

\begin{tabular}{|c|c|c|c|c|c|c|c|c|c|c|}
\cline { 2 - 11 } \multicolumn{1}{c|}{} & \multicolumn{10}{c|}{2019} \\
\cline { 2 - 11 } \multicolumn{1}{c|}{} & $1^{\circ}$ trimestre & \multicolumn{2}{c|}{$2^{\circ}$ trimestre } & \multicolumn{2}{c|}{$3^{\circ}$ trimestre } & $4^{\circ}$ trimestre & \multicolumn{2}{c|}{ minigráficos } \\
\cline { 2 - 11 } \multicolumn{1}{c|}{} & MGLU3 & LAME3 & MGLU3 & LAME3 & MGLU3 & LAME3 & MGLU3 & LAME3 & MGLU3 & LAME3 \\
\hline End. Geral & $75,02 \%$ & $81,72 \%$ & $74,25 \%$ & $80,18 \%$ & $75,90 \%$ & $78,11 \%$ & $61,78 \%$ & $77,82 \%$ & & \\
\hline End. Financeiro & $4,62 \%$ & $39,54 \%$ & $9,63 \%$ & $65,10 \%$ & $8,65 \%$ & $60,81 \%$ & $4,29 \%$ & $53,59 \%$ & & \\
\hline Grau Endiv. & $300,37 \%$ & $447,19 \%$ & $288,39 \%$ & $404,42 \%$ & $314,98 \%$ & $356,91 \%$ & $161,62 \%$ & $350,81 \%$ & & \\
\hline Cobertura de Juros & 2,89 & 0,93 & 1,70 & 1,39 & 3,69 & 1,31 & 2,32 & 2,30 & & \\
\hline Cobertura de Caixa & 2,14 & 12,85 & 2,80 & 10,99 & 2,25 & 11,74 & 1,42 & 11,08 & \\
\hline
\end{tabular}

Entre as informações contábeis usadas para calcular os Indicadores de Endividamento, encontram-se:

- O Passivo Circulante, Passivo Não Circulante e o Ativo Total para calcular o Índice de Endividamento Geral;

- O Passivo Oneroso e o Passivo Total para calcular o Índice de Endividamento Financeiro;

- O Passivo Circulante, Passivo Não Circulante e o Patrimônio Líquido para calcular o Grau de Endividamento;

- O Lucro Operacional ou EBITDA e os Juros para calcular a Cobertura de Juros; o Caixa e os Juros para calcular a Cobertura de Caixa.

Tabela 3 - Indicadores de Gestão de Ativos

INDICADORES DE GESTÃO DE ATIVOS

\begin{tabular}{|c|c|c|c|c|c|c|c|c|c|c|}
\cline { 2 - 11 } \multicolumn{1}{c|}{} & \multicolumn{10}{c|}{2020} \\
\cline { 2 - 11 } \multicolumn{1}{c|}{} & $1^{\circ}$ trimestre & \multicolumn{2}{c|}{$2^{\circ}$ trimestre } & \multicolumn{2}{c|}{$3^{\circ}$ trimestre } & \multicolumn{2}{c|}{$4^{\circ}$ trimestre } & \multicolumn{2}{c|}{ minigráficos } \\
\cline { 2 - 12 } & MGLU3 & LAME3 & MGLU3 & LAME3 & MGLU3 & LAME3 & MGLU3 & LAME3 & MGLU3 & LAME3 \\
\hline Giro do Estoque & 0,94 & 0,65 & 0,98 & 0,90 & 1,22 & 0,81 & 1,28 & 1,19 & & \\
\hline Giro do Ativo & 0,08 & 0,04 & 0,07 & 0,04 & 0,10 & 0,04 & 0,10 & 0,05 & & \\
\hline Grau Int. Capital & 12,47 & 24,80 & 14,32 & 22,80 & 10,01 & 23,61 & 9,92 & 18,96 & & \\
\hline
\end{tabular}

\begin{tabular}{|c|c|c|c|c|c|c|c|c|c|c|}
\cline { 2 - 11 } \multicolumn{1}{c|}{} & \multicolumn{10}{c|}{2019} \\
\cline { 2 - 11 } \multicolumn{1}{c|}{} & $1^{\circ}$ trimestre & \multicolumn{2}{c|}{$2^{\circ}$ trimestre } & \multicolumn{2}{c|}{$3^{\circ}$ trimestre } & \multicolumn{2}{c|}{$4^{\circ}$ trimestre } & \multicolumn{2}{c|}{ minigráficos } \\
\cline { 2 - 11 } & MGLU3 & LAME3 & MGLU3 & LAME3 & MGLU3 & LAME3 & MGLU3 & LAME3 & MGLU3 & LAME3 \\
\hline Giro do Estoque & 1,25 & 0,61 & 1,26 & 0,91 & 1,19 & 0,75 & 1,20 & 1,18 & & \\
\hline Giro do Ativo & 0,12 & 0,04 & 0,09 & 0,05 & 0,11 & 0,05 & 0,28 & 0,21 & & \\
\hline Grau Int. Capital & 8,04 & 26,59 & 11,06 & 19,56 & 9,30 & 20,87 & 3,56 & 4,83 & & \\
\hline
\end{tabular}

Entre as informações contábeis usadas para calcular os Indicadores de Gestão de Ativos, listam-se:

- A Receita Bruta e o Ativo Total, para calcular o Giro do Ativo Total; 
- O Custo do Produto Vendido e o Estoque para calcular o Giro do Estoque;

- O Ativo Total e Receita Bruta para calcular o Grau de Intensidade de Capital.

Tabela 4 - Indicadores de Rentabilidade

INDICADORES DE RENTABILIDADE

\begin{tabular}{|c|c|c|c|c|c|c|c|c|c|c|}
\cline { 2 - 10 } \multicolumn{1}{c|}{} & \multicolumn{10}{c|}{2020} \\
\cline { 2 - 11 } \multicolumn{1}{c|}{} & \multicolumn{2}{c|}{$1^{\circ}$ trimestre } & \multicolumn{2}{c|}{$2^{\circ}$ trimestre } & \multicolumn{2}{c|}{$3^{\circ}$ trimestre } & \multicolumn{2}{c|}{$4^{\circ}$ trimestre } & \multicolumn{2}{c|}{ minigráficos } \\
\cline { 2 - 11 } & MGLU3 & LAME3 & MGLU3 & LAME3 & MGLU3 & LAME3 & MGLU3 & LAME3 & MGLU3 & LAME3 \\
\hline Margem Bruta & $27,14 \%$ & $33,71 \%$ & $25,77 \%$ & $32,98 \%$ & $26,22 \%$ & $33,22 \%$ & $24,69 \%$ & $33,86 \%$ & \\
\hline Margem Operac. & $6,35 \%$ & $5,72 \%$ & $2,58 \%$ & $7,67 \%$ & $6,57 \%$ & $7,26 \%$ & $5,01 \%$ & $10,76 \%$ & \\
\hline Margem Líquida & $0,59 \%$ & $-2,24 \%$ & $-1,16 \%$ & $-0,77 \%$ & $2,48 \%$ & $0,70 \%$ & $2,18 \%$ & $5,46 \%$ & \\
\hline ROA & $0,17 \%$ & $-0,27 \%$ & $-0,31 \%$ & $-0,10 \%$ & $0,94 \%$ & $0,09 \%$ & $0,89 \%$ & $0,85 \%$ & \\
\hline ROE & $0,41 \%$ & $-1,20 \%$ & $-0,87 \%$ & $-0,48 \%$ & $2,79 \%$ & $0,22 \%$ & $3,00 \%$ & $2,56 \%$ & - \\
\hline
\end{tabular}

\begin{tabular}{|c|c|c|c|c|c|c|c|c|c|c|}
\cline { 2 - 11 } \multicolumn{1}{c|}{} & \multicolumn{10}{c|}{2019} \\
\cline { 2 - 11 } & \multicolumn{2}{c|}{$1^{\circ}$ trimestre } & \multicolumn{2}{c|}{$2^{\circ}$ trimestre } & \multicolumn{2}{c|}{$3^{\circ}$ trimestre } & \multicolumn{2}{c|}{$4^{\circ}$ trimestre } & \multicolumn{2}{c|}{ minigráficos } \\
\cline { 2 - 12 } & MGLU3 & LAME3 & MGLU3 & LAME3 & MGLU3 & LAME3 & MGLU3 & LAME3 & MGLU3 & LAME3 \\
\hline Margem Bruta & $27,98 \%$ & $34,55 \%$ & $25,35 \%$ & $35,30 \%$ & $29,29 \%$ & $36,33 \%$ & $28,59 \%$ & $35,24 \%$ & \\
\hline Margem Operac. & $9,13 \%$ & $6,97 \%$ & $8,82 \%$ & $11,27 \%$ & $10,30 \%$ & $9,71 \%$ & $7,82 \%$ & $14,39 \%$ & & \\
\hline Margem Líquida & $3,05 \%$ & $-3,01 \%$ & $8,97 \%$ & $1,44 \%$ & $4,83 \%$ & $0,19 \%$ & $2,63 \%$ & $3,25 \%$ & & \\
\hline ROA & $1,36 \%$ & $-0,33 \%$ & $3,20 \%$ & $0,21 \%$ & $1,77 \%$ & $0,02 \%$ & $0,85 \%$ & $1,85 \%$ & $>$ \\
\hline ROE & $5,43 \%$ & $-1,80 \%$ & $12,43 \%$ & $1,05 \%$ & $7,36 \%$ & $0,11 \%$ & $2,22 \%$ & $8,36 \%$ & $>$ \\
\hline
\end{tabular}

Entre as informações contábeis usadas para calcular os Indicadores de Rentabilidade, há:

- O Lucro Bruto e a Receita Líquida, para calcular a Margem Bruta;

- O Lucro Operacional (EBITDA) e a Receita Líquida, para calcular a Margem Operacional ou Margem EBITDA;

- O Lucro Líquido e a Receita Líquida, para calcular a Margem Líquida; o Lucro Líquido e o Ativo Total para calcular o Retorno do Ativo (ROA);

- O Lucro Líquido e o Patrimônio Líquido para calcular o Retorno de Capital Próprio (ROE).

Tabela 5 - Indicadores de Mercado

INDICADORES DE MERCADO

\begin{tabular}{|c|c|c|c|c|c|c|c|c|c|c|}
\hline & \multicolumn{10}{|c|}{2020} \\
\hline & \multicolumn{2}{|c|}{$1^{\circ}$ trimestre } & \multicolumn{2}{|c|}{$2^{\circ}$ trimestre } & \multicolumn{2}{|c|}{$3^{\circ}$ trimestre } & \multicolumn{2}{|c|}{$4^{\circ}$ trimestre } & \multicolumn{2}{|c|}{ minigráficos } \\
\hline & MGLU3 & LAME3 & MGLU3 & LAME3 & MGLU3 & LAME3 & MGLU3 & LAME3 & MGLU3 & LAME3 \\
\hline LPA & 0,00 & $-0,05$ & $-0,01$ & $-0,02$ & 0,03 & 0,02 & 0,03 & 0,22 & $\approx$ & 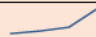 \\
\hline $\mathrm{P} / \mathrm{L}$ & 2105,98 & $-299,89$ & $-1847,98$ & $\mid-1421,68$ & 721,65 & 1286,14 & 758,05 & 94,92 & 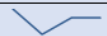 & $\sqrt{ }$ \\
\hline $\mathrm{P} / \mathrm{B}$ & 8,62 & 3,60 & 16,02 & 6,80 & 20,15 & 2,86 & 22,71 & 2,43 & & $\nearrow$ \\
\hline
\end{tabular}

\begin{tabular}{|c|c|c|c|c|c|c|c|c|c|c|}
\hline & \multicolumn{10}{|c|}{2019} \\
\hline & \multicolumn{2}{|c|}{$1^{\circ}$ trimestre } & \multicolumn{2}{|c|}{$2^{\circ}$ trimestre } & \multicolumn{2}{|c|}{$3^{\circ}$ trimestre } & \multicolumn{2}{|c|}{$4^{\circ}$ trimestre } & \multicolumn{2}{|c|}{ minigráficos } \\
\hline & MGLU3 & LAME3 & MGLU3 & LAME3 & MGLU3 & LAME3 & MGLU3 & LAME3 & MGLU3 & LAME3 \\
\hline LPA & 0,02 & $-0,06$ & 0,06 & 0,03 & 0,04 & 0,00 & 0,14 & 0,33 & & \\
\hline $\mathrm{P} / \mathrm{L}$ & 270,79 & $-232,75$ & 113,41 & 390,57 & 261,45 & 3529,04 & 86,08 & 60,22 & & \\
\hline $\mathrm{P} / \mathrm{B}$ & 14,70 & 4,18 & 14,09 & 4,11 & 19,25 & 4,00 & 10,49 & 5,03 & & \\
\hline
\end{tabular}


Entre as informações contábeis usadas para calcular os Indicadores de Valor de Mercado, há:

- O Preço por Ação e o Lucro por Ação, para calcular o Indicador Preço/Lucro (P/L);

- O Preço por Ação, Patrimônio Líquido e o número de ações da companhia, para calcular o Preço/Valor Patrimonial (P/B);

- O Lucro Líquido e o número de ações da companhia, para calcular o Lucro por Ação (LPA).

Tabela 6 - Variação dos ativos na bolsa de valores

VARIAÇÃO DOS ATIVOS NA BOLSA DE VALORES

\begin{tabular}{|c|c|c|c|c|c|c|c|c|c|c|}
\hline & \multicolumn{10}{|c|}{2020} \\
\hline & \multicolumn{2}{|c|}{$1^{\circ}$ trimestre } & \multicolumn{2}{|c|}{$2^{\circ}$ trimestre } & \multicolumn{2}{|c|}{$3^{\circ}$ trimestre } & \multicolumn{2}{|c|}{$4^{\circ}$ trimestre } & \multicolumn{2}{|c|}{ anual } \\
\hline & MGLU3 & LAME3 & MGLU3 & LAME3 & MGLU3 & LAME3 & MGLU3 & LAME3 & MGLU3 & LAME3 \\
\hline \multirow[t]{2}{*}{ V. preço das ações } & $-19,27 \%$ & $-29,48 \%$ & $91,53 \%$ & $92,04 \%$ & $24,07 \%$ & $-10,62 \%$ & $11,79 \%$ & $-18,66 \%$ & $107,06 \%$ & $-0,20 \%$ \\
\hline & \multicolumn{2}{|c|}{ IBOVESPA } & \multicolumn{2}{|c|}{ IBOVESPA } & \multicolumn{2}{|c|}{ IBOVESPA } & \multicolumn{2}{|c|}{ IBOVESPA } & \multicolumn{2}{|c|}{ IBOVESPA } \\
\hline V. índice IBOVESPA & \multicolumn{2}{|c|}{$-37,62 \%$} & \multicolumn{2}{|c|}{$34,94 \%$} & \multicolumn{2}{|c|}{$0,24 \%$} & \multicolumn{2}{|c|}{$26,59 \%$} & \multicolumn{2}{|c|}{$1,11 \%$} \\
\hline
\end{tabular}

Há também a variação do preço das ações na bolsa de valores e a variação do índice IBOVESPA.

Tabela 7 - Variação do Ativo Total

VARIAÇÃO DO ATIVO TOTAL

\begin{tabular}{|c|c|c|c|c|c|c|c|c|c|c|}
\cline { 2 - 10 } \multicolumn{1}{c|}{} & \multicolumn{10}{c|}{2020} \\
\cline { 2 - 10 } & \multicolumn{1}{c|}{$1^{\circ}$ trimestre } & \multicolumn{2}{c|}{$2^{\circ}$ trimestre } & $3^{\circ}$ trimestre & $4^{\circ}$ trimestre & \multicolumn{2}{c|}{ minigráficos } \\
\cline { 2 - 5 } & MGLU3 & LAME3 & MGLU3 & LAME3 & MGLU3 & LAME3 & MGLU3 & LAME3 & MGLU3 & LAME3 \\
\hline Ativo Total & $-10,51 \%$ & $1,97 \%$ & $16,08 \%$ & $3,58 \%$ & $6,11 \%$ & $14,46 \%$ & $12,98 \%$ & $18,62 \%$ & & \\
\hline
\end{tabular}

\begin{tabular}{|c|c|c|c|c|c|c|c|c|c|c|}
\cline { 2 - 10 } \multicolumn{1}{c|}{} & \multicolumn{10}{c|}{2019} \\
\cline { 2 - 11 } \multicolumn{1}{c|}{} & $1^{\circ}$ trimestre & \multicolumn{2}{c|}{$2^{\circ}$ trimestre } & \multicolumn{2}{c|}{$3^{\circ}$ trimestre } & $4^{\circ}$ trimestre & \multicolumn{2}{c|}{ minigráficos } \\
\cline { 2 - 5 } & MGLU3 & LAME3 & MGLU3 & LAME3 & MGLU3 & LAME3 & MGLU3 & LAME3 & MGLU3 & LAME3 \\
\hline Ativo Total & $10,74 \%$ & $15,29 \%$ & $24,04 \%$ & $-6,64 \%$ & $9,68 \%$ & $5,46 \%$ & $49,34 \%$ & $3,54 \%$ & & \\
\hline
\end{tabular}

Será analisada a variação horizontal do Ativo Total.

Tabela 8 - Variação do Lucro Líquido

VARIAÇÃO DO LUCRO LÍQUIDO

\begin{tabular}{|c|c|c|c|c|c|c|c|c|c|c|}
\hline & \multicolumn{10}{|c|}{2020} \\
\hline & \multicolumn{2}{|c|}{$1^{\circ}$ trimestre } & \multicolumn{2}{|c|}{$2^{\circ}$ trimestre } & \multicolumn{2}{|c|}{$3^{\circ}$ trimestre } & \multicolumn{2}{|c|}{$4^{\circ}$ trimestre } & \multicolumn{2}{|c|}{ minigráficos } \\
\hline & MGLU3 & LAME3 & MGLU3 & LAME3 & MGLU3 & LAME3 & MGLU3 & LAME3 & MGLU3 & LAME3 \\
\hline Lucro Líquido & $-81,66 \%$ & $-114,73 \%$ & $-309,52 \%$ & $60,19 \%$ & $419,13 \%$ & $198,90 \%$ & $6,57 \%$ & $1035,59 \%$ & $\curvearrowright$ & 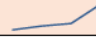 \\
\hline
\end{tabular}

\begin{tabular}{|c|c|c|c|c|c|c|c|c|c|c|}
\hline & \multicolumn{10}{|c|}{2019} \\
\hline & \multicolumn{2}{|c|}{$1^{\circ}$ trimestre } & \multicolumn{2}{|c|}{$2^{\circ}$ trimestre } & \multicolumn{2}{|c|}{$3^{\circ}$ trimestre } & \multicolumn{2}{|c|}{$4^{\circ}$ trimestre } & \multicolumn{2}{|c|}{ minigráficos } \\
\hline & MGLU3 & LAME3 & MGLU3 & LAME3 & MGLU3 & LAME3 & MGLU3 & LAME3 & MGLU3 & LAME3 \\
\hline Lucro Líquido & $-30,34 \%$ & $-143,40 \%$ & $192,67 \%$ & $159,41 \%$ & $-39,19 \%$ & $-87,46 \%$ & $-28,54 \%$ & $7632,81 \%$ & 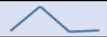 & 1 \\
\hline
\end{tabular}


Também será analisada a variação horizontal do Lucro Líquido.

Tabela 9 - Variação do EBITDA

VARIAÇÃO DO EBITDA

\begin{tabular}{|c|c|c|c|c|c|c|c|c|c|c|}
\cline { 2 - 10 } \multicolumn{1}{c|}{} & \multicolumn{10}{c|}{2020} \\
\cline { 2 - 10 } & \multicolumn{1}{c|}{$1^{\circ}$ trimestre } & \multicolumn{2}{c|}{$2^{\circ}$ trimestre } & \multicolumn{2}{c|}{$3^{\circ}$ trimestre } & $4^{\circ}$ trimestre & \multicolumn{2}{c|}{ minigráficos } \\
\cline { 2 - 4 } & MGLU3 & LAME3 & MGLU3 & LAME3 & MGLU3 & LAME3 & MGLU3 & LAME3 & MGLU3 & LAME3 \\
\hline EBITDA & $-33,35 \%$ & $-55,00 \%$ & $-56,78 \%$ & $26,22 \%$ & $279,89 \%$ & $1,74 \%$ & $-7,58 \%$ & $63,63 \%$ & & \\
\hline
\end{tabular}

\begin{tabular}{|c|c|c|c|c|c|c|c|c|c|c|}
\hline & \multicolumn{10}{|c|}{2019} \\
\hline & \multicolumn{2}{|c|}{$1^{\circ}$ trimestre } & \multicolumn{2}{|c|}{$2^{\circ}$ trimestre } & \multicolumn{2}{|c|}{$3^{\circ}$ trimestre } & \multicolumn{2}{|c|}{$4^{\circ}$ trimestre } & \multicolumn{2}{|c|}{ minigráficos } \\
\hline & MGLU3 & LAME3 & MGLU3 & LAME3 & MGLU3 & LAME3 & MGLU3 & LAME3 & MGLU3 & LAME3 \\
\hline EBITDA & $11,84 \%$ & $-50,09 \%$ & $-3,91 \%$ & $48,36 \%$ & $31,92 \%$ & $-9,01 \%$ & $-0,43 \%$ & $72,56 \%$ & $\widehat{\gamma}$ & $\leadsto$ \\
\hline
\end{tabular}

Por fim, será analisada a variação horizontal da EBITDA.

\subsection{Indicadores do Ambiente Macroeconômico}

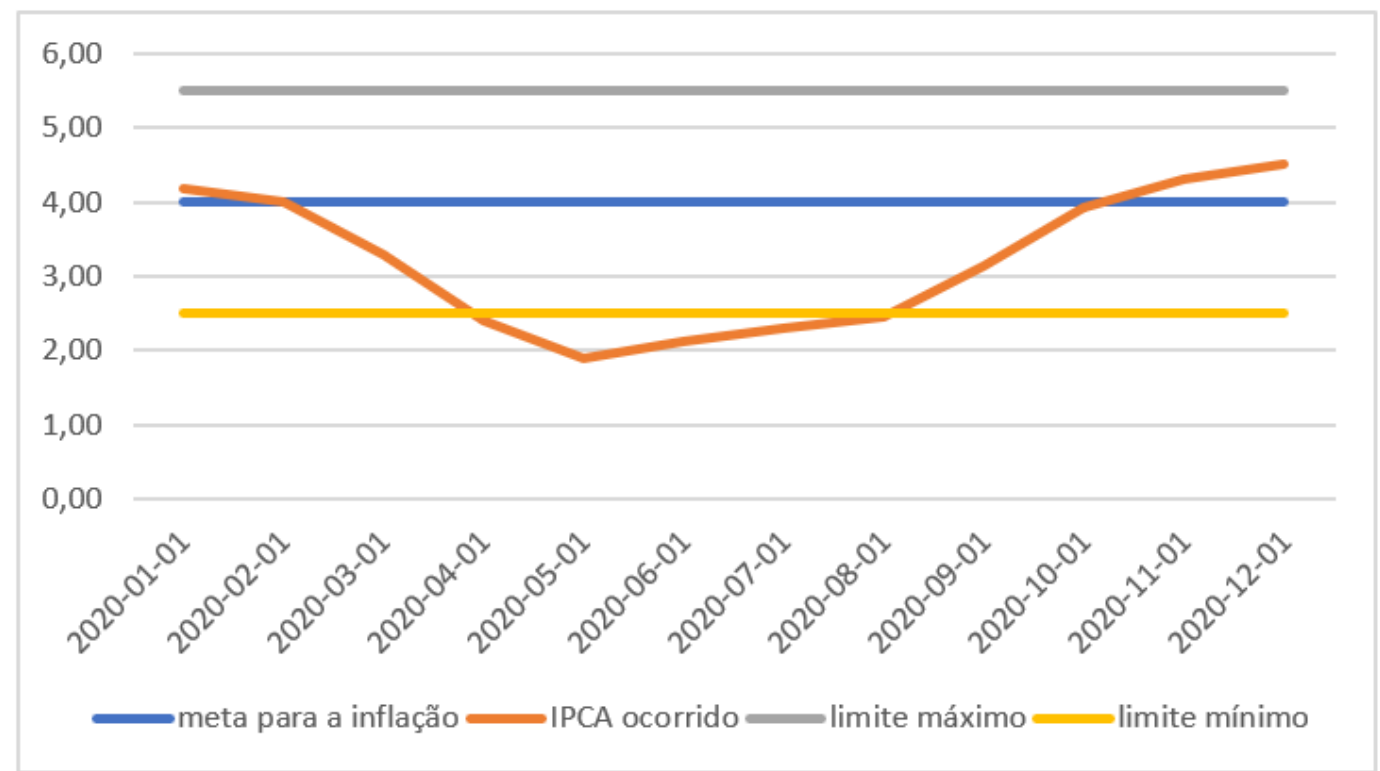

Gráfico 1 - IPCA mensal em 12 meses - 2020 


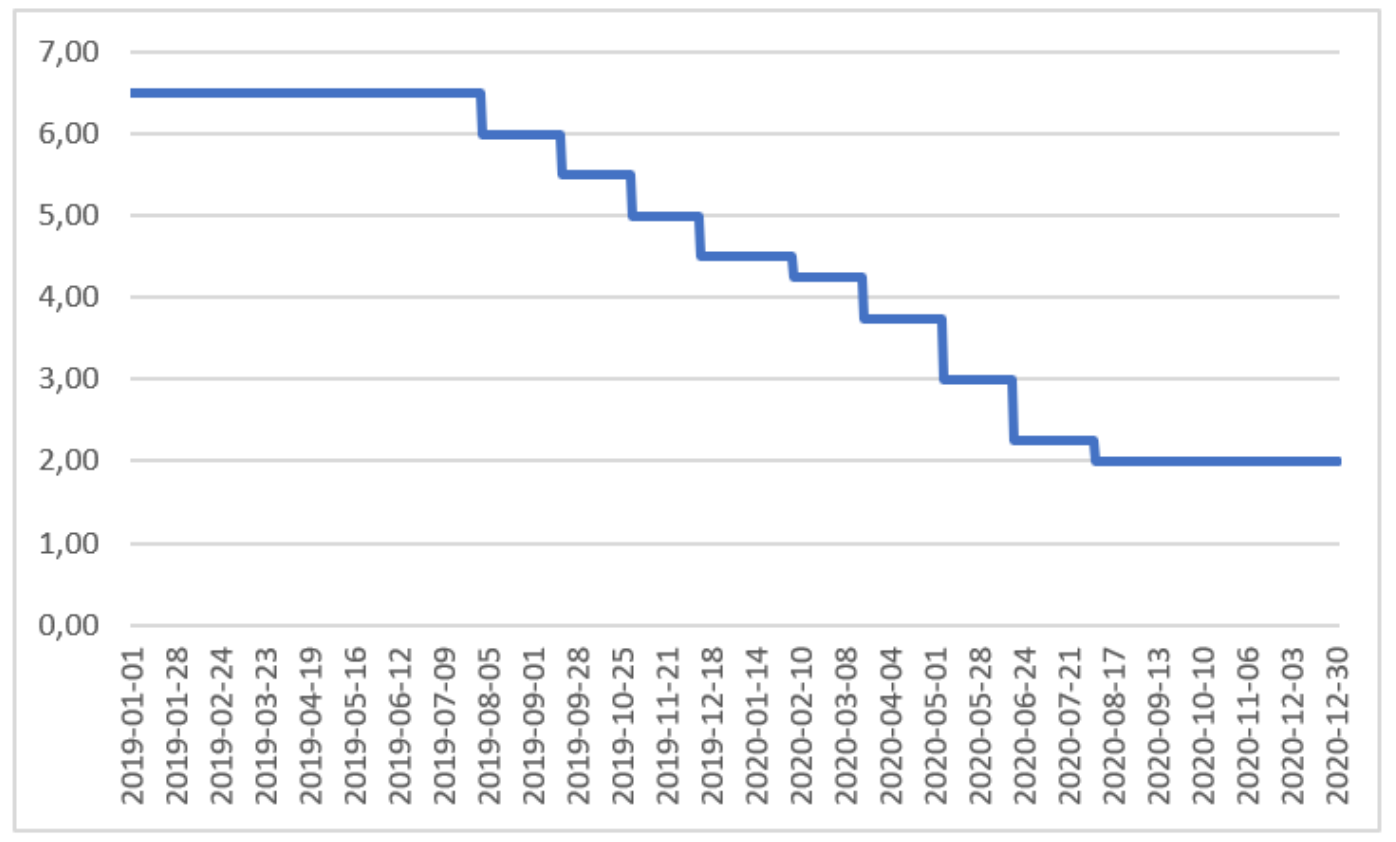

Gráfico 2 - Meta para taxa Selic entre 2019 e 2020

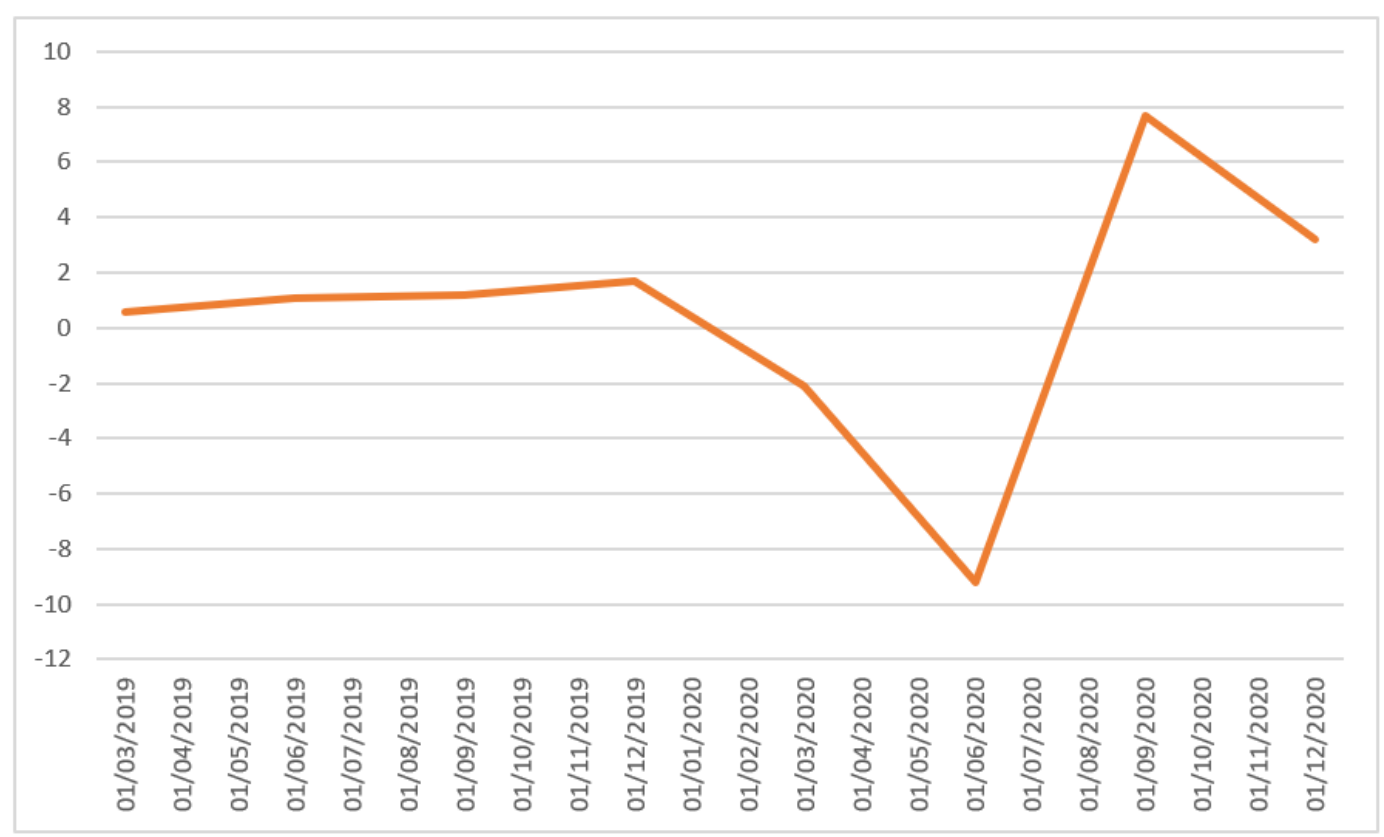

Gráfico 3 - Variação do PIB ocorrida entre 2019 e 2020 


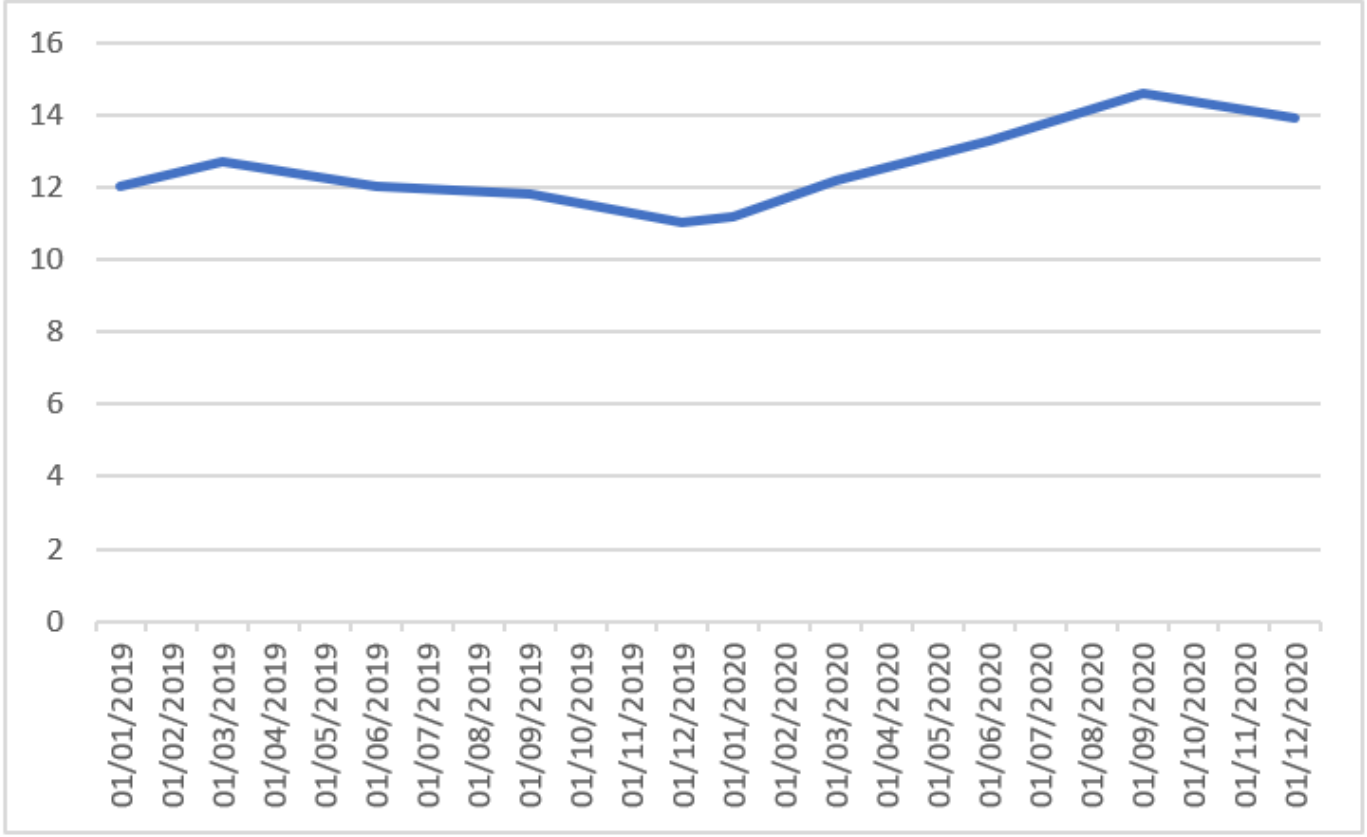

Gráfico 4 - Desemprego no Brasil - IBGE 


\section{Apresentação e análise dos resultados}

Este capítulo está organizado em quatro partes, nas quais serão analisados os quatro trimestres dos anos de 2020 com foco na diferença da rentabilidade das ações das empresas Magazine Luiza e Lojas Americanas à luz da análise de seus indicadores trimestrais e do ambiente macroeconômico.

\section{1. $01^{\circ}$ trimestre de 2020}

Tendo em vista a disseminação do coronavírus nas primeiras semanas de março, refletido na classificação como pandemia pela Organização Mundial da Saúde, entre os dias 9 e 18 de março de 2020, houve seis circuit breakers na bolsa de valores brasileira.

Assim, no $1^{\circ}$ trimestre de 2020 , entre os pregões dos dias 2 de janeiro e 31 de março de 2020, segundo a tabela 6, as ações MGLU3 e LAME3 desvalorizaram, respectivamente, $-19,27 \%$ e $-29,48 \%$. Enquanto isso, seguindo a tendência de queda global das bolsas de valores diante do risco sistêmico à economia, o índice IBOVESPA desvalorizou -37,62\%.

Segundo o BCB:

Os preços de ativos mostraram volatilidade, refletindo a preferência por ativos mais seguros em cenário de incertezas quanto:

- À magnitude e duração dos choques do preço das commodities;

- À eficácia das medidas adotadas para lidar com a pandemia e seus efeitos socioeconômicos;

- Aos efeitos sobre o comércio global e sobre a resiliência dos sistemas financeiros;

- Ao tempo necessário para o retorno à normalidade.

De acordo com a tabela 7 , no $1^{\circ}$ trimestre de 2020, o Ativo Total da Magazine Luiza (Magalu) diminuiu em relação ao último trimestre, $4^{\circ}$ trimestre de 2019. Isso ocorreu, pois a empresa usou parte de suas aplicações financeiras para pagar parte de suas contas com fornecedores. Desse modo, o Ativo Circulante da empresa diminuiu diante desse resgate parcial, ao passo que o Passivo Circulante também diminuiu diante dessa quitação parcial. 
Não obstante, mesmo com a queda do lado esquerdo do Balanço Patrimonial (Ativo Total), de acordo com a tabela 1, o Indicador de Liquidez Corrente da Magalu seguiu sólido, pois a empresa liquidou um ativo de curto prazo para pagar um passivo de curto prazo, sem prejudicar a Liquidez Corrente, ou seja, a empresa seguiu com as condições de honrar integralmente as obrigações de curto prazo (Passivo Circulante). Não apenas o indicador de Liquidez Corrente, mas também os Indicadores de Liquidez Geral e Imediata seguiram estáveis.

Essa articulação foi feita de modo a garantir a sobrevivência dos fornecedores diante das incertezas na cadeia de suprimentos promovidas pela crise do coronavírus, de suma importância para a Magalu manter sua operação sem atrasos e sem falta de produtos para seus clientes. As Lojas Americanas, por outro lado, não usaram essa estratégia, sendo esse um dos possíveis motivos para que suas ações tenham caído com mais força.

Mesmo com essa articulação, o Índice de Liquidez Seca, que leva em consideração o estoque, não passou por uma alta, de modo a revelar que o estoque não estava em um nível elevado, sem causar preocupações com a possibilidade de encalhe de estoque.

Além disso, percebe-se que as ações da Magazine Luiza desvalorizaram com menos força que as das Lojas Americanas, pois, de acordo com a tabela 3 , o Giro do Estoque da Magalu no $1^{\circ}$ trimestre de 2020 passou a superar o das Lojas Americanas, quando antes, no trimestre anterior ( $4^{\circ}$ trimestre de 2019), possuíam valores semelhantes. Dessa forma, naquele trimestre, o estoque da Magalu girou mais vezes que o das Lojas Americanas.

Outro fator para explicar a diferença de rentabilidade é o Giro do Ativo. No $1^{\circ}$ trimestre, o Giro do Ativo da Magalu é o dobro em comparação ao das Lojas Americanas, de modo que os ativos da Magalu geram faturamento com o dobro de velocidade, mesmo que o giro do ativo esteja em seu menor valor dos últimos quatro trimestres devido à queda do Ativo Total e da Receita Bruta (faturamento).

A queda do faturamento também pode ser percebida no Grau de Intensidade de Capital (GIC), que tem a Receita Bruta (faturamento) no denominador de sua fórmula. Para tal, quanto menor for o valor do faturamento, maior será o GIC. Nesse trimestre, por mais que o GIC da Magalu tenha crescido, ele ainda era apenas a metade do GIC das Lojas Americanas. 


\section{2. $02^{\circ}$ trimestre de 2020}

No $2^{\circ}$ trimestre, a crise sanitária continuou e foram estendidas as medidas sanitárias decretadas no $1^{\circ}$ trimestre, obrigando a população a se estabelecer em quarentena, desestimulando a economia, assim gerando deflação, alta no desemprego e acentuando a queda do PIB.

Nesse momento, a Magazine Luiza trabalhou sobretudo no $\mathrm{S}$ de social em suas ações de ESG, assumindo o compromisso de não demitir seus funcionários diante do aumento do desemprego; além disso, para ajudar a combater a violência doméstica contra mulheres durante a quarentena, o aplicativo da Magazine Luiza ganhou o botão de denúncias permanente.

As medidas sanitárias restritivas reduziram a atividade econômica presencial, mas, por outro lado, fortaleceram o comércio virtual. Nesse cenário as grandes varejistas, como a Magazine Luiza e as Lojas Americanas, sofreram menos que as micro, pequenas e médias empresas varejistas, pois elas possuem uma forte infraestrutura para atender à demanda das vendas virtuais, com toda a sua operação de venda online em andamento desde antes de 2020, incluindo seus sites, sistemas de pagamentos, centros de distribuição e entregadores.

Logo, as grandes varejistas, como as empresas aqui estudadas, eram praticamente as únicas a poder realizar vendas naquele período, visto que a única opção dos consumidores era a compra online, e essas eram as únicas empresas que realizavam esse tipo de venda.

No trimestre em questão, de acordo com a tabela 2, ambas as empresas aumentaram o percentual do Índice de Endividamento Geral, aumentando o percentual do ativo que está sendo financiado por recursos de terceiros e diminuindo a participação de capital próprio, podendo ser visto também pelo Grau de Endividamento, que mostra a relação entre dívida com terceiros e acionistas.

Nesse momento, ao aumentarem a participação de capital de terceiros e diminuírem a de capital próprio, elas optam pela dívida de menor custo já que a taxa de juros estava em queda, em comparação com os sócios, que exigiriam um maior retorno diante do maior risco.

Essa captação de recursos de terceiros se explica diante da estratégia financeira de que ambas as empresas decidiram aumentar seu caixa para terem mais capital em liquidez imediata, para qualquer gasto emergencial durante a crise, com os incentivos de taxas de juros menor no mercado de crédito. Por oportuno, a Magalu demonstrou a necessidade de ter caixa para honrar suas despesas com pessoal no comprometimento em não demitir seus funcionários. 
Não obstante, de acordo com a tabela 2, a Cobertura de Caixa de ambas as empresas estava em seu maior patamar se comparado aos cinco trimestres anteriores. E, por mais que a Magalu possuísse uma cobertura de caixa menor que a das Lojas Americanas no $2^{\circ}$ trimestre de 2020, seu aumento entre $01^{\circ}$ e 0 $2^{\circ}$ trimestre foi com maior força. Para tanto, a Magalu emitiu debêntures, que somaram $R \$ 800,00$ milhões, justificando o crescimento com maior força de sua Cobertura de Caixa.

De fato, por mais que o Índice de Endividamento Financeiro da Magalu tenha dobrado no $2^{\circ}$ trimestre, ele continuou em níveis menores que os das Lojas Americanas, demonstrando que o percentual do ativo que depende do passivo oneroso da Magalu é menor que das Lojas Americanas.

Ademais, há as coberturas de caixa e EBITDA, que medem se as empresas têm capacidade de pagar seus juros com seu caixa e EBITDA, respectivamente. No caso, ambas as empresas possuem capacidade de honrar seus juros, seja com seu caixa, ou com seu EBITDA.

Nesse contexto, para conter a crise financeira durante $02^{\circ}$ trimestre de 2020, o BCB diminuiu a taxa de juros, estimulando o apetite ao risco pelo investidor brasileiro, que buscou na renda variável uma rentabilidade maior do que aquela oferecida na renda fixa. Com isso, houve o aumento do número de investidores pessoas físicas na bolsa de valores, que compraram ações, entre elas, as grandes varejistas, MGLU3 e LAME3.

Os investidores, sejam os novatos da B3, sejam os antigos, valorizaram as grandes varejistas, pois estas possuíam a vantagem competitiva de suas sólidas operações de venda online ante os pequenos comerciantes, sem a possibilidade de realizarem suas vendas presenciais tradicionais. Logo, no $2^{\circ}$ trimestre, de acordo com a tabela 6, entre os pregões dos dias 1 de abril e 30 de junho de 2020, as ações MGLU3 e LAME3 se valorizaram respectivamente em $+91,53 \%$ e $+92,04 \%$. Nesse momento, marcando a tendência de alta do mercado acionário, o índice IBOVESPA valorizou $+34,94 \%$.

\section{3. $03^{\circ}$ trimestre de 2020}

No $3^{\circ}$ trimestre, de acordo com a tabela 6, as ações MGLU3 e LAME3 performaram $+24,07 \%$ e $-10,62 \%$, respectivamente. Ou seja, a partir desse trimestre, as performances das ações se descolaram, visto que uma rentabilizou positivamente e outra negativamente, sendo que o índice IBOVESPA valorizou $+0,24 \%$ nesse mesmo período. 
Como explicação desse descolamento, há o fato de a Magalu investir pesado em tecnologia para reduzir seus custos e aumentar sua margem de lucro. Como catalizador da tecnologia da empresa, a Magalu possui o Luizalabs, sua equipe interna de desenvolvimento, que, segundo a própria empresa, usa tecnologias como big data e machine learning para as diversas áreas da companhia, como atendimento, logística, financeiro e gestão de estoque, melhorando a rentabilidade da empresa.

De acordo com a tabela 4, as Margens Bruta e Operacional das Lojas Americanas foram superiores as da Magalu no $3^{\circ}$ trimestre, evidenciando que as Lojas Americanas possuíram uma maior rentabilidade na comercialização de seus produtos (Margem Bruta) e uma maior rentabilidade em sua atividade econômica (Margem Operacional), mesmo que a EBITDA, de acordo com a tabela 9, da Magalu tenha crescido com maior força no $3^{\circ}$ trimestre.

Entretanto, é visível que a Margem Líquida da Magalu, ou seja, sua rentabilidade média total, no $3^{\circ}$ trimestre de 2020 , foi maior e se recuperou com mais força em relação ao trimestre anterior em comparação com sua concorrente. Para tanto, o Lucro Líquido da Magalu, de acordo com a tabela 8 cresceu com mais força no $3^{\circ}$ trimestre em comparação com o das Lojas Americanas.

Dessa feita, diante da recuperação do Lucro Líquido, há também a recuperação do ROA, de acordo com a tabela 4. Da mesma forma que o Lucro Líquido da Magalu se recuperou com mais força, é de se esperar que seu ROA acompanhe o movimento, visto que sua fórmula possui o Lucro Líquido como numerador. Desse modo, o ROA da Magalu também se recuperou com mais força em comparação ao da Lojas Americanas.

No $3^{\circ}$ trimestre também, outro fator que potencializou a performance das ações da Magalu foi que ela seguiu com suas ações ESG, prática valorizada pelos investidores, a partir de um processo seletivo de trainees exclusivo para candidatos negros. Assim, suas ações tendem a ter uma alta na bolsa de valores em consonância com suas práticas ESG.

\section{4. $04^{\circ}$ trimestre de 2020}

No $4^{\circ}$ trimestre, de acordo com a tabela 6 , as ações MGLU3 e LAME3 rentabilizaram $+11,79 \%$ e $-18,66 \%$, respectivamente, enquanto o índice IBOVESPA valorizou $+26,59 \%$. Portanto, mais uma vez, uma empresa performou positivamente e outra negativamente, acentuando a disparidade das 
performances no ano de 2020, sendo que ambas performaram abaixo do índice IBOVESPA no trimestre em questão.

Diante dos indicadores de mercado, no $4^{\circ}$ trimestre de 2020, o Preço/Lucro $(\mathbf{P} / \mathbf{L})$ da Magazine Luiza, de acordo com a tabela 5 , se encontrava em um nível melhor que o das Lojas Americanas, de forma que os investidores estavam dispostos a pagar mais por real de lucro corrente para a Magazine Luiza do que para as Lojas Americanas. Ademais, o Preço/Valor Patrimonial (P/B), que compara o valor de mercado da empresa a seu custo, da Magazine Luiza estava superior ao das Lojas Americanas.

No $4^{\circ}$ trimestre, de acordo com a tabela 2, a Magazine Luiza possuía um Índice de Endividamento Geral semelhante ao das Lojas Americanas. No entanto, a Magazine Luiza, desde o $1^{\circ}$ até o $4^{\circ}$ trimestre de 2020 melhorou seu Índice de Endividamento Geral, aumentando o percentual de endividamento de terceiros, enquanto as Lojas Americanas apresentaram uma queda desse índice no mesmo período.

Nesse trimestre, o BCB diminuiu a taxa Selic para seu menor valor histórico, $2 \%$, de modo a estimular a economia. Desse modo, a Magazine Luiza aproveitou a baixa taxa de juros mantida pelo BCB para aumentar seu endividamento de terceiros, aquele mais barato, e diminuir a participação de capital próprio, aquele mais caro. Contudo, as Lojas Americanas foram para o caminho contrário e se endividaram com o capital próprio, o mais caro. 


\section{Conclusões e recomendações para novos estudos}

Este trabalho pretendeu investigar o porquê da diferença de 106,86 pontos percentuais da rentabilidade das ações MGLU3 e LAME3, sendo o foco do estudo os dados contábeis de ambas as empresas e o cenário macroeconômico dos anos de 2019 e 2020. Tais questões se mostram importantes, na medida que são determinantes para a valorização ou desvalorização das ações.

No $1^{\circ}$ trimestre de 2020 , ambas as ações se desvalorizaram diante do risco sistêmico à economia global e das incertezas na cadeia de suprimentos. Entretanto, diante dos indicadores financeiros apresentados, como o melhor Giro do Estoque e Giro do Ativo, as ações MGLU3 se desvalorizaram com menor força em comparação com as ações LAME3.

No $2^{\circ}$ trimestre de 2020, ambas as ações se valorizaram, pois os investidores valorizaram as grandes varejistas, que possuíam vantagem competitiva pelas suas vendas online já estruturadas. Vale ressaltar que, naquele trimestre, a Magalu trabalhou em suas ações de ESG, com o compromisso de não demitir seus funcionários e tornou permanente o botão de denúncias de violência doméstica em seu aplicativo.

No $3^{\circ}$ trimestre de 2020 , as performances das ações MGLU3 e LAME3 se descolaram, enquanto uma se valorizou, outra se desvalorizou. Isso ocorreu, pois o Lucro Líquido da Magalu cresceu com mais força no $3^{\circ}$ trimestre em comparação com o das Lojas Americanas; assim seus ROA e ROE acompanharam o movimento. Não obstante, apenas a Magalu implementou um processo seletivo exclusivo para candidatos negros, seguindo com suas ações ESG.

No $4^{\circ}$ trimestre de 2020, mais uma vez, enquanto a rentabilidade da MGLU3 foi positiva, a da LAME3 foi negativa. Esse fato se deu devido aos indicadores de endividamento, nos quais explicitam que a Magalu, desde $01^{\circ}$ trimestre de 2020 até $04^{\circ}$ trimestre de 2020, conseguiu melhorar seu perfil de endividamento ao aproveitar a baixa taxa de juros e aumentar seu percentual de endividamento de terceiros, o mais barato, diferente das Lojas Americanas.

Como hipóteses para responder à pergunta inicial do título deste estudo, há o forte investimento em tecnologia pela Magalu, que se autointitula uma empresa de tecnologia voltada para o varejo, importante para o e-commerce, 
principalmente no momento de isolamento social. Ademais, há a maior força de crescimento de importantes indicadores financeiros da Magalu em comparação com as Lojas Americanas, além das práticas ESG realizadas pela Magalu durante o ano de 2020, relevantes para os investidores precificarem a ação de maneira positiva ao longo de 2020.

Como conclusão, em 2020, diante dos argumentos, dos indicadores financeiros e do setor macroeconômico, é explicado o porquê da disparidade entre as performances das ações MGLU3 e LAME3. Enquanto uma teve a rentabilidade de $+107,06 \%$, a outra performou em $-0,20 \%$, respectivamente, entre os dias 3 de janeiro e 30 de dezembro de 2020, na bolsa de valores brasileira. E, para fins de comparação, a rentabilidade de MGLU3 foi maior e a de LAME3 menor do que o benchmark índice IBOVESPA, de rentabilidade $+1,11 \%$ no mesmo período.

\subsection{Sugestões e recomendações para novos estudos}

Como desdobramentos futuros, recomenda-se que um estudo sobre a diferença de rentabilidade das ações da Magazine Luiza e Lojas Americanas seja realizado para entender esse movimento nos anos seguintes a 2020. Outra sugestão é usar os dados contábeis da empresa para calcular os indicadores financeiros trazendo novas contribuições ao meio acadêmico. 


\section{Referências Bibliográficas}

AÇÕES ESG Magazine Luiza. Release de resultados do $4^{\circ}$ trimestre. Magazine Luiza. Disponível em: https://ri.magazineluiza.com.br/ListResultados/Central-deResultados?=0WX0bwP76pYcZvx+vXUnvg==>. Acesso em: 25 ago. 2021.

APRESENTAÇÕES de resultados trimestrais. Magazine Luiza. Disponível em: https://ri.magazineluiza.com.br/ListResultados/Central-de-

Resultados?=0WX0bwP76pYcZvx+vXUnvg==. Acesso em: 27 out. 2021.

B3. Investidores pessoas físicas bolsa de valores. B3. Disponível em: http://www.b3.com.br/pt_br/noticias/porcentagem-de-investidores-pessoa-fisicacresce-na-

b3.htm\#: :text=N\%C3\%BAmero\%20de\%20investidores\%20bate\%203,meses\%2 0de\%202021\%20e\%202020. Acesso em: 25 ago. 2021.

BANCO CENTRAL DO BRASIL. Meta para taxa Selic 2020. Banco Central do Brasil. Disponível em:

https://www.bcb.gov.br/estatisticas/grafico/graficoestatistica/metaselic. Acesso em: 25 ago. 2021.

BANCO CENTRAL DO BRASIL. Perspectivas para a inflação, Relatório Trimestral de Inflação. Banco Central do Brasil. Disponível em:

https://www.bcb.gov.br/conteudo/home-

ptbr/TextosApresentacoes/RI\%202020\%202T\%20PT_final.pdf. Acesso em: 23 ago. 2021.

BANCO CENTRAL DO BRASIL. Volatilidade preços dos ativos. Relatório de inflação. Março de 2020. Banco Central do Brasil. Disponível em:

https://www.bcb.gov.br/content/ri/relatorioinflacao/202003/ri202003p.pdf. Acesso em: 24 ago. 2021.

CIRCUIT Breakers na B3 durante a pandemia. Folha de São Paulo. Disponível em: https://www1.folha.uol.com.br/mercado/2020/03/veja-todas-as-vezes-que-abolsa-brasileira-acionou-o-circuit-breaker.shtml. Acesso em: 27 out. 2021.

COMPOSIÇÃO Acionária Lojas Americanas. Lojas Americanas. Disponível em: https://ri.lasa.com.br/governanca-corporativa/composicao-acionaria/. Acesso em: 23 ago. 2021.

COMPOSIÇÃO Acionária Magazine Luiza. Magazine Luiza. Disponível em: https://ri.magazineluiza.com.br/ShowCanal/Composicao-

Acionaria $?=x J D t O j 0 G D M v k a d q U B u l E S g==$. Acesso em: 23 ago. 2021.

DEMONSTRAÇÕES Financeiras trimestrais Lojas Americanas. Lojas 
Americanas. Disponível em: https://ri.lasa.com.br/informacoes-aosinvestidores/central-de-resultados/. Acesso em: 27 out. 2021.

DEMONSTRAÇÕES Financeiras trimestrais Magazine Luiza. Magazine Luiza. Disponível em: https://ri.magazineluiza.com.br/ListResultados/Central-deResultados?=0WX0bwP76pYcZvx+vXUnvg==. Acesso em: 27 out. 2021.

DESEMPENHOS financeiros consolidados trimestrais. Magazine Luiza. Disponível em: https://ri.magazineluiza.com.br/ListResultados/Central-deResultados?=0WX0bwP76pYcZvx+vXUnvg==. Acesso em: 27 out. 2021.

GITMAN, Lawrence. Princípios de Administração Financeira. 2. ed. São Paulo: Bookman, 2010.

IBGE. Crescimento do setor de varejo em 2020. Agência de Notícias. Disponível em: https://agenciadenoticias.ibge.gov.br/agencia-sala-de-imprensa/2013agencia-de-noticias/releases/30039-vendas-no-varejo-caem-6-1-em-dezembroe-fecham-2020-com-alta-de-1-2. Acesso em: 23 ago. 2021.

IBGE. IPCA - Variação - mês, trimestre e ano. Agência de Notícias. Disponível em: https://agenciadenoticias.ibge.gov.br/agencia-sala-de-imprensa/2013agencia-de-noticias/releases/29870-em-dezembro-ipca-sobe-1-35-e-fecha-2020em-4-52. Acesso em: 25 ago. 2021.

IBGE. Taxa de desemprego trimestral IBGE. Agência de Notícias. Disponível em: https://agenciadenoticias.ibge.gov.br/agencia-sala-de-imprensa/2013-agenciade-noticias/releases/30125-pnad-continua-taxa-de-desocupacao-e-de-13-9-etaxa-de-subutilizacao-e-de-28-7-no-trimestre-encerrado-em-dezembro. Acesso em: 25 ago. 2021.

IBGE. Variação percentual do PIB 2020 a cada trimestre. Agência de Notícias. Disponível em: https://agenciadenoticias.ibge.gov.br/agencia-sala-deimprensa/2013-agencia-de-noticias/releases/30165-pib-cai-4-1-em-2020-e-fechao-ano-em-r-7-4-trilhoes. Acesso em: 25 ago. 2021.

KOBORI, José. Análise fundamentalista: Como obter uma performance superior e consistente no mercado de ações. 2. ed. São Paulo: Alta Books, 2019.

MACHADO, Lívia. Extensão das restrições do governo do estado de São Paulo. G1. Disponível em: https://g1.globo.com/sp/sao-paulo/noticia/2020/04/06/doriaprorroga-quarentena-em-sp-ate-22-de-abril.ghtml. Acesso em: 23 ago. 2021.

OMS classifica o coronavírus como pandemia. G1. Disponível em: https://g1.globo.com/jornal-nacional/noticia/2020/03/11/oms-classifica-situacaodo-novo-coronavirus-como-pandemia.ghtml. Acesso em: 27 out. 2021.

RENTABILIDADE das ações da Lojas Americanas em 2020. Lojas Americanas. Disponível em: https://ri.lasa.com.br/servicos-aos-investidores/cotacoese-graficos/. Acesso em: 23 ago. 2021. 
RENTABILIDADE das ações da Magazine Luiza em 2020. Magazine Luiza. Disponível em: $\quad$ https://ri.magazineluiza.com.br/ShowCanal/Cotacoes-eGraficos?=641nbi0V43azAEKs3BM/mg==. Acesso em: 23 ago. 2021.

RESTRIÇÕES da Prefeitura de São Paulo. G1. Disponível em: https://g1.globo.com/sp/sao-paulo/noticia/2020/03/18/coronavirus-bruno-covasdetermina-fechamento-do-comercio-em-sp-ate-5-de-abril.ghtml. Acesso em: 23 ago. 2021.

ROSS, Stephen A.; WESTERFIELD, Randolph W.; JORDAN, Bradford D.. Fundamentos da Administração Financeira. 9. ed. São Paulo: Mcgraw-hill, 2013.

SANTIAGO, Tatiana; TOOGE, Rikardy. Restrição governo do Estado de São Paulo. G1. Disponível em: https://g1.globo.com/sp/saopaulo/noticia/2020/03/21/doria-decreta-quarentena-no-estado-de-sp-ate-o-dia-7de-abril-para-impedir-avanco-do-coronavirus.ghtml. Acesso em: 23 ago. 2021.

SILVA, Aline de Lima et al.. Análise do comportamento dos consumidores no setor varejista a partir dos novos hábitos digitais durante a pandemia da Covid 19. 2020. 76 f. Monografia (Graduação em Administração de Empresas) Centro Universitário FEl. São Bernardo do Campo, São Paulo, 2020.

TRÄSEL, Josiane Jarlise. Análise do desempenho econômico e financeiro de empresas do varejo listadas na B3: Magazine Luiza, Lojas Americanas e Via Varejo. 2018. 88 f. Trabalho de Conclusão de Curso (Graduação em Ciências Contábeis) - Curso de Ciências Contábeis, Universidade Regional do Noroeste do Estado do Rio Grande do Sul, 2018. 